\title{
A rapid method for permanent implantation of an intraoral fistula in rats
}

M. 1. PHILLIPS, CALIFORNIA INSTITUTE OF TECHNOLOGY, Pasadena, California 91109, and R. E. NORGREN, THE ROCKEFELLER UNIVERSITY, New York, New York 10021

By using polyethylene tubing instead of metal tubing, a permanent intraoral fistula can be implanted in rats without drilling through bone or shaping the tubing. $A$ detailed description of the procedure is given, which has been found to be rapid and reliable.

Several techniques have been described for delivering liquids to the tongue of an unrestrained rat, but each suffers from certain disadvantages. In the techniques of DeBold, Miller, and Jensen (1965) it is necessary to drill through the nasal sinuses, which can lead to severe hemorrhaging. The method of Gross, Trapold, and Hyde (1968) is simpler, but still requires drilling between the incisors, as well as fitting a metal hypodermic tube tc the shape of each experimental animal's muzzle. In our experience some of the rats have scratched the metal tubing and caused infections, or the catheter was dislodged. We have since used the following technique, which does not involve drilling but which is both rapid and reliable.

The cannula catheter consists of a 4-in. length of $P E 90$ polyethylene tubing with a heat flare at one end. The size of the oral opening of the catheter can be varied by sealing off the heat-softened tubing against a flat surface (a flare occurs at the same time), and reopening the tube with a needle of the desired diameter. A plastic washer ( $5 \mathrm{~mm}$ diam) is threaded onto the tubing until it rests against the heat flare. The other end of the tubing is fitted onto

Fig. 1. Detail of intraoral fistula. A. In the rat's mouth; $B$. in place on the skull. the blunt end of a curved surgical needle (No. 10-3/8 circle cutting edge).

After the rat is anesthetized, an incision is made along the skull midline, and the cranium bared. A bolt (Phillips \& Bradley, 1966) or small screws are implanted in the skull to serve as anchors for the cranial cement. The curved surgical needle is inserted in the soft flesh just lateral and rostral to the first molar (Fig. 1a). The needle is used to guide the catheter subcutaneously anterior to the zygomatic arch and out through the incision over the skull. Once the catheter is pulled snug against the inside of the cheek, the tubing is cut short at the other end and fitted over an "L-shaped" 14-mm section of 19-gauge stainless steel tubing. The steel tubing is then imbedded in cranioplastic on the skull (Fig. 1b).

To prevent blockage by food particles or saliva, a piece of PE 10 tubing is threaded into the catheter and remains there except during use. A 5-mm section of PE 100 tubing is fitted on the exposed end of the stainless steel tubing to insure the PE 10 filler is not worn off by the rat.

In experiments a pump or syringe is connected to the head-mounted steel tubing by another length of PE 90 tubing. We have regularly used volumes as low as

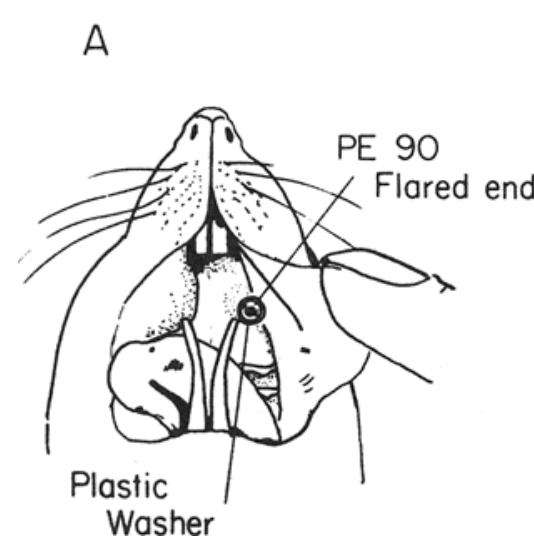

$0.04 \mathrm{cc}$ applied intraorally by this method (Norgren, 1969). More than 40 rats have been prepared in this manner, and the fistulas were always found in working order when tested over periods up to 5 months. Animals were not kept for longer periods, and none were lost due to the cannulas. Normal feeding and drinking were seen in all rats tested without interference by the cannula.

\section{REFERENCES}

DeBOLD, R. C., MILLER, N. E., \& JENSEN, D. Effect of strength of drive determined by a new technique for appetitive classical conditioning of rats. Journal of Comparative \& Physiological Psychology, 1965, 59, 102-108. GROSS, D. M., TRAPOLD, M. A., \& HYDE, T. S. A simple technique for delivering liquids directly to the mouth of an unrestrained rat. Journal of the Experimental Analysis of Behavior, 1968, 11, 191-195.

NORGREN, R. E. Diencephalic systems related to gustatory reinforcement. Unpublished PhD thesis, The University of Michigan, 1969.

PHILLIPS, M. I., \& BRADLEY, P. B. Micro-miniature connectors used as permanent electrode holders in the rat. Journal of the Experimental Analysis of Behavior, 1966, 9, 291.

\section{NOTE}

1. This work was supported by USPHS grants to James Olds, and we thank Dr. Olds for his interest and help.

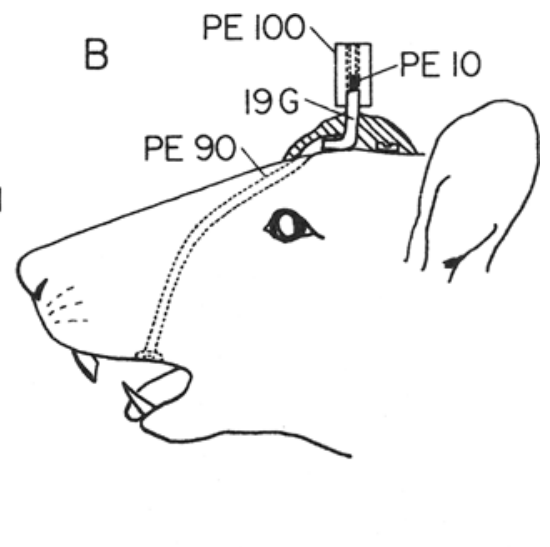

